\title{
Empathetic and Pro-social Awareness in Primary School Students: A Case Study
}

\author{
Fatima Rehan Dar \\ Department of Education, Shaheed Zulfiqar Ali Bhutto Institute of Science and Technology (SZABIST) 90 Clifton, Pakistan
}

Copyright $\bigcirc 2016$ by authors, all rights reserved. Authors agree that this article remains permanently open access under the terms of the Creative Commons Attribution License 4.0 International License

\begin{abstract}
The study addressed a cognitive-affective gap in a primary English curriculum and noticed whether the curriculum, texts and class activities utilized empathetic and pro-social themes in teaching English language. The findings from the document review, interviews and observations revealed that the said themes were underrepresented in the curriculum, textual content and class activities. Moreover, the teachers also did not demonstrate the required empathetic and pro-social skills in classrooms. The regular English lessons depicted a highly cognitive focus and proved teachers as inadequate role models for the said skills. Data from parents' questionnaires revealed that the stated skills were taught in theory and not in practice. However, when integrated cognitive-affective lessons were used, they brought forth a significant increase in student interest in academic work and raised awareness about the stated themes. The study was significant in terms of raising the importance of the stated skills in an educational set up and proved that a cognitive-affective approach in schools could prepare helpful and caring individuals for the society.
\end{abstract}

Keywords Affective, Empathy, Pro-social, Cognitive-affective Curriculum

\section{Introduction}

Affective education occupies key space in education. It endeavors to enhance students' growth in attitudes, interests, character, values, and other areas within the social-emotional domain. Although the division of education into the above categories is part of a well-structured plan, the transformation of them in the school curriculum usually fragments them into an inequitable balance. This mainly means that the curricula of schools are usually framed keeping in view the cognitive or the knowledge domain. The result is a mass production of individuals who may have advanced academic skills to pursue their careers further but do not have adequate empathetic and pro social (E \& P) skills to adjust well into the society at large. Khatib, Sarem and
Hamidi [19] therefore advocate an educational experience that must employ meaningful contexts of real communication among students in the process of making them "people." Such a curriculum ensures wholesome personality development. McLaughlin and Alexander [22, p 18] are of the view that:

The aims of the curriculum should be to develop students who can work co-operatively, with initiative, independence, perseverance and flexibility; who can move easily in the emotional domain; who can communicate effectively; tolerate ambiguity; reason sensibly; plan and solve problems; who can obtain and use information; learn how to learn; evaluate themselves and others; possess perseverance; tolerate difference and have an ability to work in multicultural setting.

The need, therefore, is to support a curriculum which takes into its fold the defined domains with equitable balance. Only then it can be claimed that schools focus on all aspects of human development which includes cognitive, affective and psychomotor domains. According to Burnside [5] this integration is all the more important as contemporary societies are victims of ever increasing global, local and interpersonal tensions.

\subsection{Background of the Study}

The basic argument behind the conception of this research plan is that students need affective education, E \& $\mathrm{P}$ in particular, together with academic development. A fine balance is required between the cognitive and affective domains of education. Only then education can be of meaningful consequence. Tudor [34] refers to this cognitive-affective association as the major mainstay of the humanistic theory of education. In Pakistan, however, there is a lot of emphasis on academic achievement. Affective training is usually not well emphasized in the curriculum. Peterson [28] claims that proactive attention to the affective domain is overlooked in many schools. The curricular objectives, textual materials and activities do not actively 
portray E \& $\mathrm{P}$ themes. Sometimes a lean presence is felt through some project work or an occasional activity in schools. But, those are not enough to make students well aware of the stated themes. The result, therefore, is that students become generally good in academic skills but remain short of developing affective skills. They are generally not well informed and aware of appropriate E \& P skills which they can make part of their everyday behaviors. Morelock [25] comments that when school curriculum focuses solely upon the cognitive realm, the uneven development of the other domains may be enhanced. The need in Pakistan, therefore, is to achieve a fine balance between the affective and cognitive domains especially when other countries have begun to shift their focus from all cognitive to cognitive-affective integrated teaching.

\subsection{Statement of Problem}

The purpose of education should be the preparation of individuals who maintain cognitive as well as affective abilities in a fine balance. Brackett and Rivers [4] contend that schools must meet the social and emotional developmental needs of students for effective teaching and learning to take place and for students to reach their full potential. The lack of cognitive-affective curricular focus is evident in most school systems in Pakistan. However, there is hardly any empirical evidence available to prove the cognitive-affective gap in the school curriculum, textual materials, classroom activities and teacher behavior. This particular study is designed to address this gap. Moreover, the study is intended to demonstrate that a cognitive-affective approach in the English language curriculum leads to affective awareness among students, E \& $P$ in this particular case, and raises academic interest of students in classrooms. The overall purpose therefore is to achieve a fine cognitive-affective balance and to demonstrate that affective skills can be taught in fair unison with cognitive skills without compromising the latter.

\subsection{Objectives of the Study}

The major objectives of this study were to:

1. analyze the English curriculum and textual materials from grades 1-5 for the presence of $\mathrm{E} \& \mathrm{P}$ themes.

2. explore how teachers manifested and taught $\mathrm{E} \& \mathrm{P}$ skills in classrooms from grades 1-5

3. raise awareness of $\mathrm{E} \& \mathrm{P}$ skills among grades 1-5 students through E \& P integrated textual materials and activities.

4. observe students' interest in academic work while they focused on E \& P integrated class activities.

5. explore the ways parents considered the teaching of E \& P skills in schools

\subsection{Significance of the Study}

The study was set to address the cognitive-affective gap in the English language curriculum at the primary level. The study, was significant in terms of:

- $\quad$ addressing the cognitive-affective gap in the English language curriculum at the primary level

- $\quad$ indicating a lack of E \& P focus in the curriculum and the choice of English textual materials

- demonstrating that textual materials at the primary level were used to enhance cognitive abilities only; the focus on $\mathrm{E} \& \mathrm{P}$ contents of texts was overlooked

- $\quad$ revealing that teachers were inadequate role models for the demonstration of E \& P skills

- $\quad$ establishing that a cognitive-affective approach could raise awareness among students about E \& P skills without jeopardizing the academic development

- determining that a cognitive-affective approach in the classroom could enable students to better engage in academic work

- demonstrating cognitive-affective strategies that could be used in English language classrooms at the primary level

- $\quad$ making teachers and parents realise that both academic and affective domains were important contributors in education

\subsection{Literature Review}

In contrast to the advocacy of Bloom [3] to finely blend educational activities into cognitive, affective and psychomotor domains, schools, particularly in Pakistan, generally follow a cognitive approach towards framing and implementing of the curricula. Ornstein and Hunkins [26, p.7] state that, "Today, however, demands for educational excellence and academic productivity have resulted in an emphasis on cognition, not humanism". Iscan and Senemoglu [16] claim that in the process of education, acquisition of cognitive behaviors is emphasized most, whereas affective characteristics are ignored as their acquisition takes a long time due to the fact that it is relatively hard to make children acquire such characteristics. However, systematic development of cognitive skills is not solely responsible in the academic journey of a student. Hasse [12] is of the view that a child's learning occurs in cognitive, affective, psychomotor, cultural and linguistic domains. In his opinion if learning cannot be isolated, neither then can the curriculum itself. Cooper [7, p.21] is of the view that, "only by raising awareness and radically altering the contexts in which genuine carers work, can we improve the personal, social, moral and academic development of future generations". Roeper (1995) as cited by [10] too states that when affective issues are addressed and social emotional needs met, students face their challenges with emotional balance and appropriate coping mechanisms that promote success in reaching personal potential.

Ferguson [10] claims that there are many theories which attest to the connection between the affective domain and cognitive processing. Tudor [34] opines that John Dewey, Francis Parker and Charles Judd are the proponents of 
humanistic education theories as they think that the unbalanced teacher pupil relationship needs to be humanized in order to ensure an optimal affective framework for the personal development of the students. Bandura [2] advocates a social-cognitive learning theory (SCL) that interlink an individual's emotional domain with the cognitive capabilities in a social context. The development of emotional capacity directly impacts cognitive competence. Simonson and Maushak (2001) as cited in [24] advocate the affective-cognitive consistency theory that suggests that the affective component of the attitude system may be changed by providing new information (changing the cognitive component) through a persuasive message. Once the individual has processed the new information, he or she will undergo an attitude change to bring the knowledge and affect into harmony.

Empathy and prosocial skills are important ingredients of affective skills. Rushton and Sorrentino (1981) as cited in [14] regard pro-social, sharing and helping behavior, as well as altruism and empathy as overlapping concepts that have common social and developmental roots. Krevan and Gibbs (1996) as cited in [14] suggest that the literature on relationships between $\mathrm{E} \& \mathrm{P}$ behavior suggests that the two concepts are closely related and are influenced to a great deal by early relationship experiences. Teachers contribute hugely towards the E \& P development of students. Cooper [7] cites a study which examines the role of empathy in teacher-student relationships and its relevance to moral modeling. Work with sixteen teachers and student teachers reaffirm the significance of affective education in academic set ups. The findings reveal that intensive positive interaction generates engagement, rapid processing and emotional attachment. The research confirms the importance of affective issues in learning and the role of empathy in the facilitation of personal, social, moral and academic development. Many educators have rated caring to be a chief trait of teachers. Stronge (2007) as cited in [35] identifies caring; fairness and respect; interactions with students; enthusiasm and motivation; attitude toward teaching; and reflective practice as chief affective traits of teachers.

Classrooms and the curricula must act as active agents to ensure healthy E \& P developments. Here teachers are the main sources who present the curricula in a way as to bridge the gap between cognitive and affective domains. Spivak, Lipsey, Farran and Polanin [29, p.5] state that the, "examples of instructional practices include but are not limited to positive reinforcement, direct instruction, permissive instruction, induction, reasoning, modeling, empathy arousing techniques, emotional socialization, moral exhortation, practice or rehearsal of prosocial behavior, external reward, socializer nurturance or emotional warmth, and assignment of social responsibility". Hamburg and Hamburg [13] suggest that pro-social behavior can be fostered when children are given specific empathy training. He thinks that role-taking exercises reduce the level of bias by employing both cognitive and emotional empathy. $\mathrm{He}$ further suggests jigsaw classrooms, and intergroup dialogue programs to teach E \& P skills. Elias, Zins, and Weissberg [9] also claim that when teachers encourage students to restate their ideas in positive terms, tolerate students' errors, clarify the students' intent, and give students time to think, more creative and thoughtful responses follow. Moreover, when teachers focus on topics like effects of behavior on other people's feelings, well-being and ability to learn students become more sensitive towards such behaviors. Other methods recommended by them to enhance $\mathrm{E} \& \mathrm{P}$ behaviors are storytelling and biography, group discussion, role play, self-awareness and self-regulation, self-reflection and goal-setting, artistic expression and cooperative and small group learning. Louie [21] is also of the view that when students develop personal connection with literature, empathy may be a specific form of such aesthetic response. Galda and Beach [11] are of the view that texts, readers, and contexts are inseparable from one another. When readers respond to texts, associate with characters, themes, and culture, the feelings of empathy are invoked and make students more sensitive. Taylor and Larson [33] reiterate the same and report that when discussing literature, the teacher can solicit students' emotional reactions to themes, characters, and plot development.

A cognitive-affective approach towards teaching and learning is, therefore, needed in schools to manifest a wholesome concept of education. Lashari, Alias, Kesot and Akash [20] explain cognitive-affective approach as an approach that focuses on the student's cognitive learning with the support of affective learning. Pace [27] advocates a cognitive-affective approach towards teaching and learning and opines that the said approach provides a philosophical foundation from which teachers can base their teaching outcomes ensuring that both the emotional and traditional cognitive realms are being delivered. Jingna [18] too hints at exploring the student's potential to stimulate the mutual effect between cognition and emotion as it has seen to have a significant improvement of education career.

\section{Research Methodology}

The research design for the purpose of study was qualitative in nature. Savenye and Robinson [30] opine that qualitative research involves highly detailed but rich descriptions of human behaviors and opinions. This particular qualitative research followed the case study approach towards the investigation of the stated problem. According to McMillan [23] a case study is an in-depth analysis of one or more events, settings, programs, social groups, communities or individuals in their natural context. It is an investigation of one entity, which is carefully defined and characterized by time and place.

\subsection{Research Design}

Figure 1 states the research design of the study. 


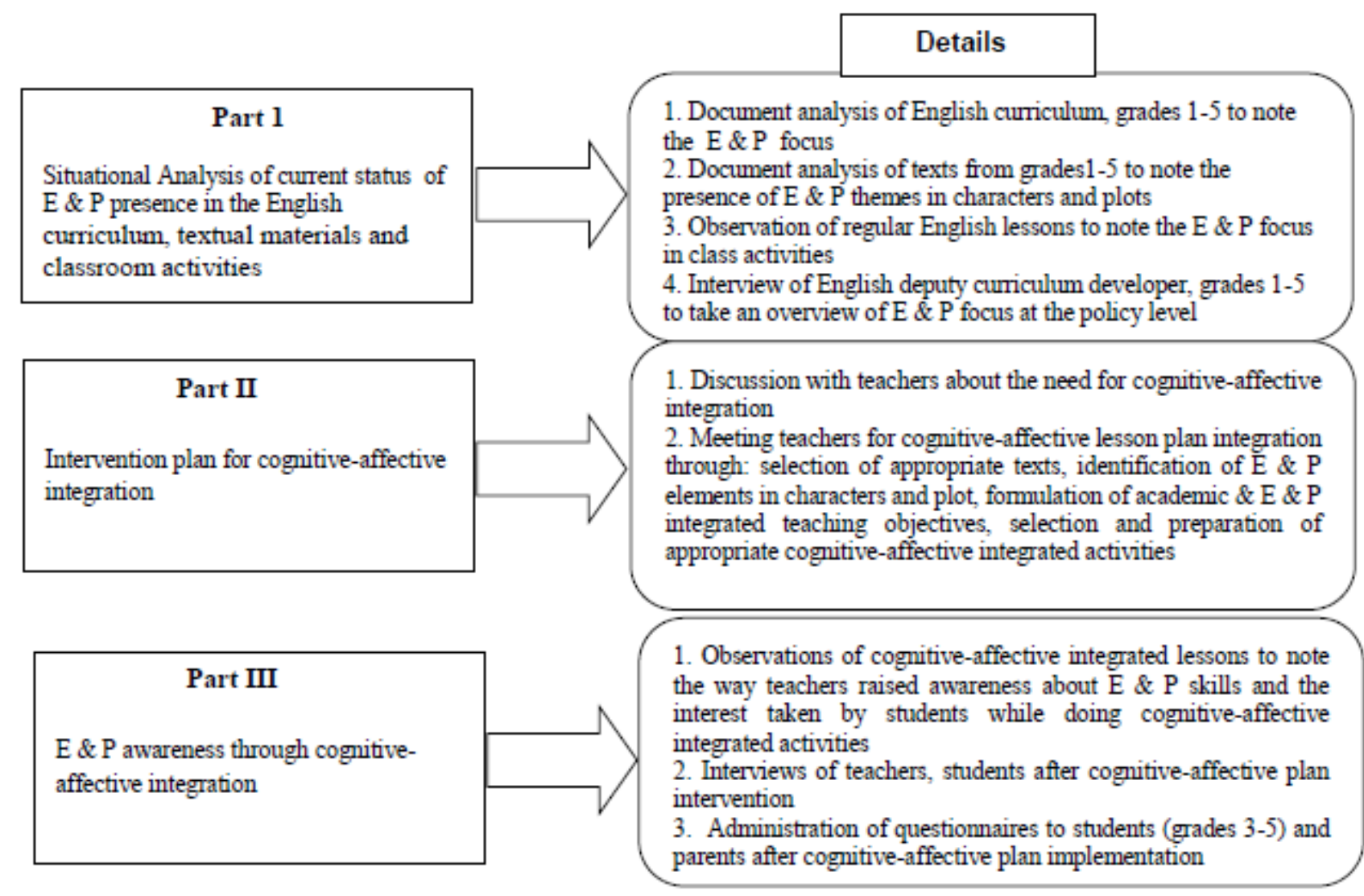

Figure 1. Research Design

\subsection{Research Instruments}

The following research instruments were used for the investigation of the study:

\subsection{Document Analysis}

According to Wellington [36] studying documents allowed a researcher to see the way an organisation portrayed itself in print. English language curriculum document from grades 1-5 was reviewed against an E \& P checklist in terms of its program of study, philosophy of teaching English language, teaching strategies, time allocation given to four skills, worksheets done in classrooms, story themes and achievement targets of each grade. Similarly, textbooks from grades1-5 were also read and analyzed for the E \& $\mathrm{P}$ themes that they projected through characters and story plots, E \& $\mathrm{P}$ themes, projected by themes of caring, sharing and helping others were noted.

\subsection{Observations of Classes}

According to McMillan [23] observations make the researcher spend an extended period of time in a setting to develop a rich understanding of the phenomenon under study. Observations were conducted in two rounds. Round 1, made a situational analysis of the current status of $E$ \& $P$ skills in the classrooms from grades 1-5. Round 2 of observations was held when the teachers taught cognitive-affective lessons after the intervention phase (part II of study) and the interest of students in academic work, their awareness about E \& P themes and change in teacher behavior were noted against the same checklist which was used in Round 1. The checklist is derived from the empathetic and pro-social attributes of teachers given by Zakrzewski (39) and Watson, Miller, Davis and Carter [35]. In terms of teacher's behavior, the checklist focused on teacher's demonstration of $\mathrm{E} \& \mathrm{P}$ skills in classes, her enthusiasm towards teaching, her friendliness with students, her ability to make students feel responsible towards themselves and their peers. In terms of using $\mathrm{E} \& \mathrm{P}$ values in lessons, the checklist focused on involving students in class discussions, encouraging collaborative work and helping other peers, motivating quieter students to participate in class work, taking care of the intellectual and emotional needs of students, highlighting $\mathrm{E} \& \mathrm{P}$ themes in texts and raising awareness about them through activities.

\subsection{Interviews}

Wellington [36] remarks that interviewing aids investigation of the phenomenon under study and prompts things that cannot be observed. Interview of the primary (grades 1-5) English language deputy curriculum developer was taken to take an overview of the objectives of the primary English language curriculum. After the E \& P texts were taught in classrooms, students and teachers were 
interviewed to get their impressions about the importance of teaching and learning $\mathrm{E} \& \mathrm{P}$ skills and to register their experience of getting exposure to these themes.

Students' and parents' questionnaires. Questionnaires were also prepared for students (grades 3-5) as it was assumed that they would not be able to speak fully and comprehensively in interviews. Some questionnaires were also given to parents to seek their opinions about the teaching of E \& P themes in classrooms from grades1-5.

\subsection{Sample Selection}

The type of sampling procedure used for the purpose of this particular study was purposeful. According to McMillan [23] in qualitative studies participants were selected purposefully. He went on to claim that in purposeful sampling, the researcher selected particular individuals or cases because they would be particularly informative about the topic. As cited by Wiersma and Jurs [38, p.346] in case studies of organizations it is impractical to, "interview everyone involved, review all possible related documents and observe all instruction". This was the reason to do internal sampling which according to Bogdan and Biden (as cited in Wiersma \& Jurs, [38, p.61] would identify the individuals to be interviewed, the documents to be reviewed, and the classes to be observed. McMillan [23] reiterated the same and said that internal sampling led the researcher to select those individuals, times, and documents that would provide the greatest amount of information.

The study is conducted in one of the 'elite' chain of English medium schools in Lahore. The word 'elite' refers to those schools that cater to children coming from upper class and upper middle class sections of society. The rationale behind choosing this particular school system is that it is the largest school system in the world and caters to 247,000 students in nine countries. So, the school system is selected as it is representative of maximum student population studying in the private sector of Pakistan and hopes to give the greatest amount of the desired information. Two branches of the school system were selected for the purpose of study.

Table 1 explains the numbers of teachers and students who participated in the study.

Table 1. Number of Teachers and Students who Participated in Study

\begin{tabular}{|c|c|c|}
\hline Grade & Teachers & Students \\
\hline 1 & $\begin{array}{c}1+1 \\
\text { (two sections of Grade 1 were observed) }\end{array}$ & $22+22$ \\
\hline 2 & $\begin{array}{c}1+1 \\
\text { (two sections of Grade 2 were observed) }\end{array}$ & $22+22$ \\
\hline 3 & 1 & 23 \\
\hline 4 & $1+1$ & 23 \\
\hline 5 & 1 & 23 \\
\hline \multicolumn{2}{|c|}{ Total teachers: 8 Total students: 157} \\
\hline
\end{tabular}

\section{Results and Analysis}

The following section will report the results and analysis of the English language curriculum and textual materials, classroom observations, interviews and questionnaires:

\subsection{Results and Analysis of the Curriculum Document}

The results of the curriculum document indicated a clear lack of focus in incorporating the $\mathrm{E} \& \mathrm{P}$ elements in the English curriculum. The program of study, philosophy of teaching English, managing learning in the classroom, teaching strategies and scheme of work of the curriculum presented an insufficient projection of $\mathrm{E} \& \mathrm{P}$ themes through which knowledge and awareness of the said skills could not be accomplished. Even if the teaching objectives, texts, class activities, worksheets, questions and vocabulary words in the curriculum documents hinted at the E \& $\mathrm{P}$ themes, the said themes were not highlighted and stressed to a satisfactory level. They were discussed as passing references and not taken as solid points for discussion.

This trend led to the conclusion that the focus of the curriculum was highly cognitive in nature and the main purpose of it was the progressive development of the language skills with very little provision for the affective elements of E \& P skills. However, the E \& P focus could be maintained with the same curriculum as the elements rested there and just needed a clear focus and attention. For example, the activities like role plays, dramatizations, group and pair work, discussions, artistic expressions, jigsaw reading, and reflective talks were spread sporadically throughout the curriculum and could have become active and vibrant forums for raising awareness about $\mathrm{E} \& \mathrm{P}$ themes as well but such methods were not used satisfactorily for this purpose. Elias et al. [9] also outlined storytelling, role plays, self-awareness and self-regulation, self-reflection, artistic expression, cooperative and small group learning as important methods to enhance social and emotional learning among students.

The curriculum required a fine blend of cognitive and affective skills which was reported as inadequate. Chaskin and Rauner [6] shared the same concern and stated that the emotional needs of children were often left out of discussions about how to improve student performance. They continued to assert that the caring interactions between teachers, students, and parents often made the difference between positive school experiences and frustration or alienation. The same curricular targets, therefore, could be used to enhance awareness about E \& P skills as well. Noddings (1992) as cited by [6] was of the same view and suggested that curricula could be organized around themes of caring or that teachers could weave such themes into regular material by sharing their interests with students or by responding spontaneously to events in the school and community. What the entire curriculum under discussion needed was a shift in focus from a highly cognitive to a 
cognitive-affective curriculum. The same cognitive elements, i.e. teaching of English language skills, could be fine-tuned with the affective elements of $\mathrm{E} \& \mathrm{P}$ skills for the development of awareness and knowledge about both domains.

\subsection{Results and Analysis of the Texts Used from Grades 1-5}

Table 2 explains the proportion in which $\mathrm{E} \& \mathrm{P}$ themes appeared in routine lesson and story time texts from grades $1-5$.

Table 2. Percentages of the Routine Lesson and Story Time Texts with E \& P Themes

\begin{tabular}{|c|c|c|c|c|}
\hline Grades & $\begin{array}{c}\text { Time } \\
\text { allocation } \\
\text { routine } \\
\text { lessons }\end{array}$ & $\begin{array}{c}\% \text { of } \\
\text { routine } \\
\text { lesson texts } \\
\text { with E \& P } \\
\text { themes }\end{array}$ & $\begin{array}{c}\text { Time } \\
\text { allocation } \\
\text { story time } \\
\text { sessions }\end{array}$ & $\begin{array}{c}\% \text { of story } \\
\text { time texts } \\
\text { with E \& } \\
\text { P themes }\end{array}$ \\
\hline 1 & $\begin{array}{c}140 \text { min. per } \\
\text { week }\end{array}$ & $64 \%$ & $\begin{array}{c}45 \text { min. per } \\
\text { week }\end{array}$ & $15 \%$ \\
\hline 2 & $\begin{array}{c}140 \text { min. per } \\
\text { week }\end{array}$ & $57 \%$ & $\begin{array}{c}45 \text { min. per } \\
\text { week }\end{array}$ & $10.2 \%$ \\
\hline 3 & $\begin{array}{c}160 \text { min. per } \\
\text { week }\end{array}$ & $60 \%$ & $\begin{array}{c}40 \text { min. per } \\
\text { week }\end{array}$ & $28 \%$ \\
\hline 5 & $\begin{array}{c}220 \text { min. per } \\
\text { week }\end{array}$ & $50 \%$ & $\begin{array}{c}30 \text { min. } \\
\text { twice a } \\
\text { month }\end{array}$ & $15 \%$ \\
\hline per week & 230 minutes & $\begin{array}{c}30 \text { minutes } \\
\text { once a week }\end{array}$ & $41 \%$ \\
\hline
\end{tabular}

The results as projected above indicated a gradual reduction of themes as the grades progressed. However, Cotton [8] argued that older children were better able to recognize emotive states in other people, more capable of relating to and sharing others' feelings, able to feel empathy for more diverse kinds of people, and more willing to express their empathetic response in generosity toward others. The study of the routine lesson texts and the activities that ensued from them also revealed that the curriculum developers and teachers who selected texts and developed text related activities did not attempt to integrate the cognitive domain with the affective. This could also be attributed to either a lack of awareness or a deliberate omission to do the same. Kazemek (1996) as cited by [37] argued and said, "We are teaching our children and young adults not to care through our acts of commission and omission" (p.6)

\subsection{Results and Analysis of Rounds 1 And 2 of Observations}

In both rounds of observations, the physical environment of the classes, student interest in academic work teacher behavior and use of $E \& P$ values in lessons were made subjects of observations. Round 1 of observations, which was made without any intervention, proved that the physical environment of classes did not promote $E \& P$ learning. It also determined teachers as inadequate role models for the projection of $E \& P$ skills. This could be attributed to their lack of professional development training in the affective domain. Jennings and Greenberg [17] reiterated the same and commented that there was explicit lack of pre-service and in-service training aimed at teachers' personal development in the affective domain. Moreover, the observations for round 1 authenticated the findings of the English curriculum and textual materials and further highlighted cognitive focus in teaching and learning. The all cognitive focus resulted in lack of interest of students in academic work.

Round 2 of observations was held after the intervention plan was discussed with teachers. Whereas there was no significant improvement in the physical environment of the classroom and teacher behavior, there was a surge in the interests that students took while doing cognitive-affective lessons. Also, teachers were able to use the cognitive-affective approach well. Pace [27] is of the view that the cognitive-affective approach provides a framework in which both academic and affective information and knowledge can be transmitted and individually interpreted by the students. The teachers, therefore, exploited the E \& P values extremely well in all lessons through linking $\mathrm{E} \& \mathrm{P}$ values with academic language targets, bridging the gap between theory and practice by linking $\mathrm{E} \& \mathrm{P}$ values to real life contexts, relating the textual themes and characters to real life situations, making E \& $\mathrm{P}$ awareness emerge through the use of all language resources, i.e. listening, speaking, reading, writing, grammar and vocabulary and reinforcing $\mathrm{E}$ $\& \mathrm{P}$ themes through recaps.

\subsection{Results and Analysis of Interviews and Questionnaires}

The focused group interviews of teachers revealed that students lacked $E$ \& $P$ skills mostly because parents accorded no values to such skills. Chaskin and Rauner [6] reported that family was central in promoting caring behavior in children. Moreover, they declared the curriculum as academic driven. This was also reiterated by the deputy curriculum developer in her interview. They further claimed that $\mathrm{E} \& \mathrm{P}$ skills were taught through plain moral lessons and deductive teaching, hence it had no positive impact on students. Furthermore, they regarded the integration of E \& $P$ themes in texts and activities as vital for awareness of the same in students and revealed that students took better interest in academic work through the integration of $\mathrm{E} \& \mathrm{P}$ themes in the lessons. The teachers confessed their lack of training in the affective domain. Some of the teachers showed their surprise at the integration of $\mathrm{E} \& \mathrm{P}$ themes in the regular lessons and frankly admitted that they could never think of such integration. They valued the cognitive-affective link and expressed their desire to get further training for better integration of the two domains. The deputy curriculum developer in her interview also expressed the same inadequacy of not making affective education part of the professional development programs for teachers.

The findings of the students' interviews and 
questionnaires revealed that students had a very moralistic vision of $\mathrm{E} \& \mathrm{P}$ skills, attributable mainly to the deductive teaching of the same. However, they reported that the integrated cognitive-affective lessons were very enjoyable and interesting learning experiences for them. They stayed on task yet enjoyed the learning experience. Moreover, the students displayed adequate awareness of $\mathrm{E} \& \mathrm{P}$ themes in all the lessons that were taught to them. They were able to locate E \& P themes well and identify E \& P characters and plots well through lessons, texts or activities. They were also able to transcend well beyond texts and activities and were successful in thinking about the applicability of E \& P skills in real life contexts. The cognitive-affective integrated lessons, therefore, proved a very effective medium to raise awareness about $\mathrm{E} \& \mathrm{P}$ themes among students.

The findings of parents' questionnaires reported that parents considered E \& P skills very important components for their children's personality development. However, it was also concluded that this was implied in theory because the evidence suggested that students did not demonstrate E \& P skills well in schools. This was evident through Round 1 of observations and also revealed through teachers' interviews. The parents' questionnaires also authenticated the view that school's role was vital in the E \& P development of children and for that teachers ought to be exemplary role models. The questionnaires also testified the view that books played a vital role in raising $\mathrm{E} \& \mathrm{P}$ awareness. The analysis of the questionnaires led to the conclusion that children shared and reported E \& P school based experiences with parents when at home. Thus they found the $\mathrm{E} \& \mathrm{P}$ information important enough to be highlighted and shared. However, it was seen through the data that more of such instances were required for better and sound E \& P awareness among students. The parents' questionnaires also led to the conclusion that parents regarded themselves as good role models to teach $\mathrm{E} \& \mathrm{P}$ skills to their children. This was again implied in theory and not in practice. The evidences collected from other sources suggested the opposite. The teachers in their interviews blamed parents for being inadequate and bad role-models for the development of E \& P skills. The same was revealed through round 1 of observations. The conclusions drawn from the parents' questionnaires, therefore, authenticated and enriched the conclusions drawn from other data collection instruments.

\section{Conclusions}

The findings of Part I of the study led to the conclusion that the English language curriculum, textual materials, class lessons, teacher behavior did not manifest the presence and manifestation of $E \& P$ themes and skills. Moreover, students did not display adequate interest in cognitive focused lessons. Silverman [31, p.326] gave a warning against this stance and commented that, "without focusing attention to their affective development, we risk the advancement of intellect without ethics".
The findings of Part III of the study, however, revealed that cognitive-affective lessons led to more enlivened classrooms. The classrooms manifested more group and pair work activities, teacher student discussions, role plays, presentations and other collaborative work. The physical environment turned from teacher-centered to learner centered. Athanases, Christiano and Lay [1] also notified the benefits of learner centered classrooms which created caring communities through constant student engagement. Bracket and Rivers [4] also supported the notion of integrated cognitive-affective classrooms having an influence on students' social-emotional wellbeing and academic improvement. Students therefore spoke well in groups and discussions, read with eagerness and wrote with concentration. There were hardly any student disruptions. Students helped each other in groups and shared ideas well. They also took turns in responding and respected each other's point of view. This led to the conclusion that the cognitive-affective link in lessons increased the interest of students in work. Moreover, students showed more awareness of E \& $P$ skills and opined that they had learnt to 'share and care' from the experience. The findings further revealed that parents considered the school as the most important place for the development of E \& P skills. Most of them thought teachers to be the most important sources to inculcate $\mathrm{E} \& \mathrm{P}$ behaviors among school children. Jennings $\&$ Greenberg $[17$, p.500] reiterated the same and stated that, "Teachers are role models who continuously induce and respond to the emotional reactions of their students". They also considered themselves as adequate role-models for the enculturation of $\mathrm{E} \& \mathrm{P}$ skills among their children, a stance which the teachers strongly refuted in their interviews and so was authenticated through round 1 of observations.

\section{Recommendations}

The findings, analysis and conclusions drawn from the data collected through document and textbook analysis, observation of classrooms, interviews and questionnaires led to the following recommendations:

1. Curriculum document as a guiding document should formally suggest cognitive-affective integration.

2. Professional development programs need an E \& P focus so that teachers teach with pedagogical prowess

3. Textual content and classroom activities should manifest $\mathrm{E} \& \mathrm{P}$ themes and need an $\mathrm{E} \& \mathrm{P}$ focus for better student awareness

4. The school culture needs an E \& P focus for better affective impact on students

5. There should be appropriate rewards for E \& P behavior demonstration in school.

6. Schools should encourage establishment of school based programs that help children deal with emotions and also promote community service. 


\section{Future Directions}

The present research has indicated that $\mathrm{E} \& \mathrm{P}$ behaviors have not caught enough empirical attention in Pakistan. Hojat [15] indicates the same and adds that most often scholars of human behavior have focused on abnormal personality development. As a result, positive aspects of personality, such as pro-social behavior and empathy, have not received sufficient empirical attention. More research, therefore, needs to be done on $\mathrm{E} \& \mathrm{P}$ skills and $\mathrm{E} \& \mathrm{P}$ behavior development in Pakistani school children at the primary and secondary levels. The findings of the research can then be used for creating better awareness of affective skills and behaviors among them. According to Philips [29, p.50], "teaching empathy takes years, a lifetime, of learning". Further research in the field of affective education is, therefore, needed to elevate its importance and raise its appeal for society. It is a neglected and less researched area in Pakistan and it is hoped that with more research and more empirical findings the domain of affective education is solidified and made more active through better integration with academic curricula, healthier school cultures, improved student-teacher relationships and behaviors and more affectively designed and enriched texts and activities for classroom use.

\section{REFERENCES}

[1] Athanases, SZ, Christiano D, \& Lay, E. Fostering empathy and finding common ground in multiethnic classes. The English Journal. 1995; 84.26-34.

[2] Bandura, A. (2005). The evolution of social cognitive theory. In K.G - Smith \& M.A - Hill (Eds).Great Minds in management.(pp. 9 - 35) Oxford: Oxford University Press.

[3] Bloom, BS. Taxonomy of educational objectives, Handbook 1: The cognitive domain. New York, NY: David Mckay Co Inc; 1956.

[4] Brackett MA, Rivers SE. Transforming students' lives with social and emotional learning. International Handbook of Emotions in Education. 2014 Apr 16:368-88.

[5] Burnside R. Stepping into someone else's shoes: The effects of empathy development on student behavior. Rising Tide. 2012; $5: 1-4$.

[6] Chaskin RJ, Rauner DM. Youth and caring: An introduction. Phi Delta Kappan. 1995 May 1; 76(9):667.

[7] Cooper B. Empathy, interaction and caring: Teachers' roles in a constrained environment. Pastoral Care in Education. 2004 Sep 1;22(3):12-21.

[8] Cotton K. Developing empathy in children and youth. Northwest Regional Educational Laboratory; 1992.

[9] Elias MJ, Zins JE, Weissberg RP. Promoting social and emotional learning: Guidelines for educators. Adolescence. 2000 Jan 1; 35(137):221.
[10] Ferguson S. A case for affective education: Addressing the social and emotional needs of gifted students in the classroom. Virginia Association for the Gifted Newsletter. 2006:1-3.

[11] Galda L, Beach R. Response to literature as a cultural activity. Reading research quarterly. 2001 Jan 3; 36 (1):64-73.

[12] Haase SE. Thoughts on an Integrated Approach to Curriculum. Journal of American Indian Education. 1981 May; 20(3):32-3.

[13] Hamburg DA, Hamburg BA. Learning to live together: Preventing hatred and violence in child and adolescent development. Oxford University Press; 2004 Mar 10.

[14] Hojat M. Development of prosocial behavior and empathy in the hand that rocks the cradle. The family in the new millennium: World voices supporting the natural clan. 2007; 3:98-106

[15] Hojat M. Ten approaches for enhancing empathy in health and human services cultures. Journal of health and human services administration. 2009 Apr 1:412-50.

[16] Iscan CD, Senemoglu N. Effectiveness of values education curriculum for fourth grades. Egitim ve Bilim. 2009 Jul 1; 34 (153): 1 .

[17] Jennings PA, Greenberg MT. The prosocial classroom: Teacher social and emotional competence in relation to student and classroom outcomes. Review of educational research. 2009 Mar 1; 79 (1):491-525.

[18] Jingna DU. Application of humanism theory in the teaching approach. Higher Education of Social Science. 2012 Jul 31;3(1):32-6

[19] Khatib M, Sarem SN, Hamidi H. Humanistic education: Concerns, implications and applications. Journal of Language Teaching and Research. 2013 Jan 1;4(1):45-51.

[20] Lashari TA, Alias M, Kesot MJ, Akasah ZA. An affective-cognitive teaching and learning approach for enhanced behavioral engagements among engineering students. Engineering Education. 2013 Dec 1; 8(2):65-78.

[21] Louie B. Development of empathetic responses with multicultural literature. Journal of Adolescent \& Adult Literacy. 2005 Apr 1; 48(7):566-78.

[22] McLaughlin C, Alexander E. Reframing personal, social and emotional education: Relationships, inclusion, diversity, agency, participation and dialogue. Warwick: Naple. 2004.

[23] McMillan, JH. Educational Research: Fundamentals for the consumer. Boston: Pearson Education Inc. 2008

[24] Miller M. Teaching and learning in affective domain. Emerging perspectives on learning, teaching, and technology. Retrieved March. 2005; 6: 2008.

[25] Morelock MJ. Giftedness: The view from within. Understanding our gifted. 1992; 4(3):1.

[26] Ornstein AC, Hunkins FP. Curriculum--foundations, principles, and issues. Boston: Pearson 2013.

[27] Pace, B. Teaching and learning in social science and humanities: A cognitive-affective approach to tertiary teaching. 2006. Available from: http://researcharchive.winte c.ac.nz/652/1/Teaching_and_learning_in_social_science_an d humanities.pdf 
[28] Peterson JS. An argument for proactive attention to affective concerns of gifted adolescents. Prufrock Journal. 2002 Nov 1; 14(2):62-70.

[29] Phillips LC. Nurturing empathy. Art education. 2003 Jun 1; 56(4):45-53.

[30] Savenye WC, Robinson RS. Qualitative research issues and methods: An introduction for educational technologists. Handbook of research for educational communications and technology. 1996:1171-95.

[31] Silverman LK. Affective curriculum for the gifted. Comprehensive curriculum for gifted learners. 1994:325-46.

[32] Spivak AL, Lipsey MW, Farran DC, Polanin JR. Registration for a Systematic Review: Instructional Strategies for Enhancing Prosocial Behavior in Children and Youth: A Systematic Review and Meta-Analysis.2014. Available from: http://www.campbellcollaboration.org/lib/project/317/

[33] Taylor HE, Larson S. Social and emotional learning in middle school. The Clearing House. 1999 Jul 1; 72(6):331-6.

[34] Tudor M. The potential of humanistic learning in the Romanian school in the context of new education methods and of the present society. Euromentor Journal-Studies about education. 2014(03):64-76

[35] Watson S, Miller T, Davis L, Carter P. Teachers' Perceptions of the Effective Teacher. Research in the Schools. 2010 Sep 1; 17(2).

[36] Wellington J. Educational research: Contemporary issues and practical approaches. London: Viva-Continuum. 2015 Jan 29.

[37] White B. Caring and the teaching of English. Research in the Teaching of English. 2003 Feb 1:295-328.

[38] Wiersma W., Jurs SG. Research methods in education: An introduction. Boston: Pearson. 2009

[39] Zakrzewski V. Four ways teachers can show they care. Greater Good Science Center (GGSC), The Science of a Meaningful Life. 2012 Sep 18. 